\title{
Asthma therapy modulates priming-associated blood eosinophil responsiveness in allergic asthmatics
}

\author{
J.C. Grutters*, L. Brinkman**, M.M. Aslander**, J.M.M. van den Bosch*, \\ L. Koenderman**, J-W.J. Lammers**
}

Asthma therapy modulates priming-associated blood eosinophil responsiveness in allergic asthmatics. J.C. Grutters, L. Brinkman, M.M. Aslander, J.M.M. van den Bosch, L. Koenderman, J-W.J. Lammers. C ERS Journals Ltd 1999.

ABSTRACT: Eosinophils play an important role in the pathogenesis of asthma. Several pro-inflammatory responses of eosinophils are primed in vivo in this disease. The aim of the present study was to investigate whether regular antiasthma treatment could modulate priming-sensitive cytotoxic mechanisms of human eosinophils.

In a randomized, two-centre, double-blind parallel group study, the effect of 8 weeks of treatment with salmeterol xinafoate $50 \mu \mathrm{g}$ b.i.d., beclomethasone dipropionate $400 \mu \mathrm{g}$ b.i.d. or both on pulmonary function and the activation of primingsensitive cytotoxic mechanisms of eosinophils, i.e. degranulation of eosinophil cationic protein (ECP) in serum, and activation of isolated eosinophils in the context of induction of the respiratory burst and release of platelet-activating factor (PAF) were tested. These effects were evaluated in 40 allergic asthmatics before and $24 \mathrm{~h}$ after allergen inhalation challenge.

Whereas baseline forced expiratory volume in one second (FEV1) improved in all treatment groups, only treatment with a combination of salmeterol and beclomethasone significantly inhibited the allergen-induced increase in serum ECP, and (primed/ unprimed) PAF-release, suggesting inhibition of eosinophil priming after allergen challenge. In contrast to the combination therapy, monotherapy with beclomethasone had no influence on allergen-induced PAF-release, suggesting an additional antiinflammatory effect of salmeterol during combination therapy. Monotherapy with beclomethasone inhibited the prechallenge serum-treated zymosan (STZ) $(0.1 \mathrm{mg}$. $\mathrm{mL}^{-1}$ )-induced respiratory burst and the allergen-induced increase in serum ECP levels, reflecting pre- and postchallenge anti-inflammatory effects. During monotherapy with salmeterol, an allergen-induced increase in serum ECP concentration and STZ $\left(0.1 \mathrm{mg} \cdot \mathrm{mL}^{-1}\right)$-induced respiratory burst was observed, suggesting that treatment with salmeterol alone had no effect on priming-sensitive eosinophil cytotoxic mechanisms.

In conclusion, this study shows that standard asthma therapy leads to inhibition of eosinophil priming of cytotoxic mechanisms in vivo.

Eur Respir J 1999; 14: 915-922.

Eosinophils are important effector cells involved in the inflammatory reaction that characterizes allergic asthma [1]. In contrast to normal individuals, in the peripheral blood of allergic asthmatics, eosinophils are found having a primed phenotype $[2,3]$. There are many indications that cytotoxic mechanisms in these cells are markedly upregulated $[4,5]$. Inhalation of allergens is often used as a model for studying allergic asthma. After allergen challenge, a late asthmatic response can be found, which is of particular interest because it represents an inflammatory reaction and involves the recruitment and activation of CD4+ T-cells and eosinophils [6]. Activation of eosinophils results in release of platelet-activating factor (PAF), leukotriene $\mathrm{C}_{4}$, reactive oxygen species and cytotoxic basic proteins such as serum eosinophil cationic protein (ECP) [7]. Six hours after challenge, blood eosinophils exhibit a more pronounced primed phenotype and, $24 \mathrm{~h}$ after challenge, a rise occurs in the number of blood eosinophils and levels of serum ECP [8-10].
Depts of Pulmonary Diseases, *Sint Antonius Hospital, Nieuwegein, **University Hospital Utrecht, the Netherlands.

Correspondence: J-W.J. Lammers

Dept of Pulmonary Diseases

Rm E 03.824

University Hospital Utrecht

P.O. Box 85500

3508 GA Utrecht

the Netherlands

Fax: 31302542155

Keywords: Allergen challenge

asthma

beclomethasone

eosinophil priming

salmeterol

therapy

Received: April 231998

Accepted after revision May 281999

This study was supported by a grant from Glaxo Wellcome b.v., the Netherlands.
International guidelines on asthma management recommend that, in patients with moderate-to-severe asthma who still have symptoms on treatment with low-dose inhaled corticosteroids, the first step should be to increase the dose of inhaled glucocorticosteroids [11]. An alternative to increasing the dose of steroids is to proceed to the next step, with the addition of a long-acting selective $\beta_{2}$-agonist [11]. These therapeutic guidelines were supported by recent studies on the effects of different treatments on lung function and symptom scores [12-14]. The authors believe that by also studying the effects on inflammatory responses important new information can be provided for the clinical management of a group of patients seen frequently in general practice.

Glucocorticosteroids like beclomethasone dipropionate are anti-inflammatory drugs. Salmeterol xinafoate is a long-acting selective $\beta_{2}$-agonist, with possible antiinflammatory properties [15-18]. In vitro salmeterol is a potent inhibitor of the release of inflammatory and 
spasmogenic mediators from human lung [15]. In vivo studies in guinea-pigs have shown that PAF-induced eosinophil influx into the lungs is inhibited by salmeterol [16]. Tool et al. [17] described the inhibition of chemotaxis of human eosinophils in vitro by salmeterol. In asthmatic patients, salmeterol both inhibited the allergen-induced early and late phase of bronchoconstriction and prevented the accompanying rise in nonspecific bronchial responsiveness, pointing at an anti-inflammatory effect [18]. Whether salmeterol has significant anti-inflammatory effects in vivo in humans, therefore, requires further research.

The aim of the present study was to investigate whether regular antiasthma treatment including salmeterol could modulate the priming-sensitive cytotoxic mechanisms of human eosinophils. Therefore, the effects of 8 weeks of treatment with salmeterol xinafoate $50 \mu \mathrm{g}$ b.i.d., beclomethasone dipropionate $400 \mu \mathrm{g}$ b.i.d. or both on pulmonary function and the activation of priming-sensitive cytotoxic mechanisms of eosinophils, i.e. degranulation of ECP in serum, activation of oxygen radical production and production of PAF. These effects were evaluated before and after allergen challenge.

\section{Materials and methods}

\section{Patients}

Forty adult asthmatics were selected from patients attending the University Hospital Utrecht and the Sint Antonius Hospital, Nieuwegein, the Netherlands. The patients had moderate asthma according to the definition of the American Thoracic Society [19]. All subjects had a history of episodic wheezing and impaired lung function. This was checked in previous general practitioner and hospital records. All patients were on regular inhaled $\beta_{2^{-}}$ agonists and 12 patients were taking inhaled corticosteroids, which were stopped 6 weeks before allergen inhalation challenge. None of them used oral corticosteroids in maintenance dose during the 12 months prior to the study. At the time of the study, all patients were in a stable state with respect to their asthma and showed no evidence of systemic or other respiratory disease.

On the day of admission, the forced expiratory volume in one second (FEV1) was $>60 \%$ of the predicted normal value before bronchodilator therapy in all patients. At enrolment, all were required to show increased bronchial hyperresponsiveness to histamine (provocative concentration of agent causing a $20 \%$ fall in FEV1 $\left(\mathrm{PC}_{20}\right)<4.0$ $\left.\mathrm{mg} \cdot \mathrm{mL}^{-1}\right), a>15 \%$ reversibility in FEV1 from baseline 15 min after inhalation of $400 \mu \mathrm{g}$ salbutamol and a fall in FEV1 within $1 \mathrm{~h}$ after allergen inhalation challenge of $\geq 20 \%$. All patients had blood eosinophilia ( $>5 \%$ ), raised levels of total serum immunoglobulin E ( $\mathrm{IgE}$ ) and specific $\operatorname{IgE}$ antibodies to either house dust mite, cat, dog or rabbit allergen. They also showed positive immediate-type skinprick test reactions to these allergens and hence were considered atopic. Patients were excluded if they had been hospitalized for any aspect of their asthma or had required a change in medication because of an acute exacerbation of symptoms in the 2 months before the study. The demographic data of the participating patients are given in table 1 . The study was approved by the hospital ethical committee and all patients gave their written informed consent.

\section{Study design}

The study had a double-blind parallel group design. It was divided into a 2-week run-in period (screening day and entry day), an 8-week treatment period and a 2-week follow-up period (table 2). At the end of the run-in period, the subjects were randomized to receive either $50 \mu \mathrm{g}$ of salmeterol b.i.d., $400 \mu \mathrm{g}$ of beclomethasone b.i.d. or 50 $\mu \mathrm{g}$ of salmeterol b.i.d. in combination with $400 \mu \mathrm{g}$ of beclomethasone b.i.d. All medication was inhaled from a Diskhalerß (Glaxo Wellcome). For ethical reasons, placebo control patient group was not used as the risk of an exacerbation of asthma would have been too high in these patients because of the severity of the asthma and the length of the study, during which two allergen inhalation challenges were performed.

Each subject was studied at the lung function department on nine separate days. On the entry day, demographic data, details of concurrent medication and the results of a spirometric test performed before and after inhalation of $400 \mu \mathrm{g}$ salbutamol were recorded. A skin test was carried out using common inhaled allergens to determine which allergen to use in the allergen inhalation test. In addition, urine and blood samples were taken for the determination of routine biochemical and haematological parameters and urine analysis. At the end of the run-in period, a skin-prick test and an inhalation challenge with histamine were performed (visit 2) followed $48 \mathrm{~h}$ later by an allergen inhalation challenge (visit 3 ). Twenty-four hours later, the histamine test was repeated (visit 4). On visit 4 (the end of the run-in period), the 8-week treatment period started, during which the patients visited the hospital after 4 weeks (visit 5) so that therapy compliance could be checked by counting the used study medication and a spirometric test before and after inhalation of $400 \mu \mathrm{g}$ salbutamol performed. At the end of the treatment period, a further histamine challenge was performed (visit 6), followed $48 \mathrm{~h}$ later by an allergen inhalation challenge (visit 7). This test was performed $1 \mathrm{~h}$ after the patient had taken the study

Table 1. - Characterization of study groups

\begin{tabular}{|c|c|c|c|c|c|c|c|c|}
\hline Group & $\begin{array}{c}\text { Patients } \\
\mathrm{n}\end{array}$ & $\begin{array}{l}\mathrm{Age}^{\#} \\
\mathrm{yrs}\end{array}$ & $\begin{array}{l}\text { Sex } \\
\text { F/M }\end{array}$ & $\begin{array}{l}\text { PC20,hist. } \\
\mathrm{mg} \cdot \mathrm{mL}^{-1}\end{array}$ & $\begin{array}{l}\text { PC20,all. } \\
\mathrm{BU} \cdot \mathrm{mL}^{-1}\end{array}$ & $\begin{array}{l}\text { FEV1 } \\
\% \text { pred }\end{array}$ & $\begin{array}{l}\text { Specific IgE } \\
\mathrm{kU} \cdot \mathrm{mL}^{-\mathrm{P}}\end{array}$ & $\begin{array}{l}\text { Total IgE } \\
\mathrm{kU} \cdot \mathrm{mL}^{-1}\end{array}$ \\
\hline & 15 & $26 \pm 5$ & $7 /$ & & 2) & & & 310 \\
\hline xinafoate & 13 & $31 \pm 7$ & $8 / 5$ & $0.50(0.16-2.20)$ & $138(12-2720)$ & $79 \pm 3$ & $41(1-$ & $264(42-1800)$ \\
\hline Combination & 12 & $27 \pm 6$ & $6 / 6$ & $0.38(0.10-3.12)$ & $68(12-349)$ & $79 \pm 5$ & $49(25-100)$ & $303(81-800)$ \\
\hline
\end{tabular}

Data are presented as mean \pm SEM or median (range). F: female; M: male; PC20,hist; PC20,all.: provocative concentration of histamine and allergen, respectively, causing a $20 \%$ fall in forced expiratory volume in one second; BU: biological units; IgE: immunoglobulin E. 
Table 2. - Design of the study

\begin{tabular}{|c|c|c|c|}
\hline Period & PC20,hist & $\begin{array}{l}\text { Lung } \\
\text { function }\end{array}$ & $\begin{array}{l}\text { Allergen Blood sample } \\
\text { challenge taken }\end{array}$ \\
\hline
\end{tabular}

\section{Baseline period (2 weeks)*}

Visit 1 , day 1

Visit 2, day 12

Visit 3, day 14

Visit 4, day 15

Treatment period $(8 \text { weeks })^{+}$

Visit 5, day 43

Visit 6, day 69

Visit 7 , day 71

Visit 8 , day 72

Follow-up period (2 weeks) ${ }^{\#}$

Visit 9, day 86

*: treatment with salbutamol $400 \mu \mathrm{g}$ p.r.n.; ${ }^{+}$: treatment with study medication (beclomethasone $400 \mu \mathrm{g}$ b.i.d. salmeterol 50 $\mu \mathrm{g}$ b.i.d. or both) and salbutamol $400 \mu \mathrm{g}$ p.r.n.; " : medication replaced by appropriate asthma medication at the discretion of the investigator. PC20,hist: provocative concentration of histamine causing a $20 \%$ fall in forced expiratory volume in one second. +: test performed; -: test not performed.

medication with the same allergen and dose as used in visit 3. Twenty-four hours later, another histamine test was performed and the study medication was replaced by appropriate asthma medication (visit 8). At visit 3, 4, 7 and 8, blood samples $(50 \mathrm{~mL})$ were taken for determination of inflammatory parameters. At the follow-up visit 2 weeks later (visit 9), possible adverse events were evaluated and a spirometric test performed before and after $400 \mu \mathrm{g}$ salbutamol. Apart from the study medication, the subjects were allowed to use salbutamol Rotadisks $\mathbb{R}$ (Glaxo Wellcome; $400 \mu \mathrm{g} \cdot$ blister $^{-1}$ via an eight-place Diskhaler $\AA$ ) for symptomatic relief.

\section{Allergens}

Commercial preparations of SQ 503 house dust mite (Dermatophagoides pteronyssinus), SQ 555 cat (Felis catus), SQ 553 dog (Canis familiaris) and 15.07 rabbit (Oryctolagus cuniculus) for inhalation challenge and skinprick tests were obtained from Allergologisk Laboratorium (Copenhagen, Denmark).

\section{Lung function measurements}

Salbutamol inhalation was stopped $\geq 8 \mathrm{~h}$ and study medication $\geq 12 \mathrm{~h}$ before all lung function tests. Only the allergen inhalation challenge at visit 7 was performed $1 \mathrm{~h}$ after the subjects had taken the study medication administered by the investigator in the lung function department. Lung function was measured using a water-filled spirometer. Bronchodilatation was assessed by means of the increase in FEV1 $10 \mathrm{~min}$ after inhalation of $400 \mu \mathrm{g}$ salbutamol.

\section{Inhalation provocation tests}

Bronchial responsiveness to histamine was determined using a standard bronchoprovocation technique, as described by COCKCROFT et al. [20]. Airway response to allergen was determined by 2-min inhalations (tidal breathing) at 10-min intervals, as previously described [21]. The allergen challenge was preceded by a 2-min inhalation of an aerosol of buffer $(0.03 \%$ human serum albumin and $0.5 \%$ phenol in phosphate-buffered saline, $\mathrm{pH} 7.4$ ) to which none of the patients reacted with a fall in FEV1 of $>10 \%$ from initial values. Increasing concentrations of allergen aerosol were delivered through a nebulizer (Model 646, DeVilbiss, Inc., Somerset, PA, USA). This nebulizer was connected to the central chamber of an inspiratory and expiratory three-way valve box with an expiratory aerosol filter (Sterivent Filter; DAR, Mirandola, Italy). Antigen was diluted from stock solutions $\left(10,000\right.$ biological units $\left.(\mathrm{BU}) \cdot \mathrm{mL}^{-1}\right)$. The diluent was the same buffer as used for the negative control. The weakest allergen solution used for the first inhalation was calculated from the skin-prick titration test and the preantigen PC20 to histamine according to COCKCROFT et al. [22]. Allergen inhalation tests were routinely started two doubling dilutions below this prediction. At visit 3, inhalations were performed with stepwise doubling of the dose of antigen until the FEV1 fell by $\geq 20 \%$ within 20 min following allergen exposure. At visit 7 , the same allergen and cumulative dose was used as at visit 3 . The FEV1 and peak expiratory flow were monitored at 15-min intervals for the first hour, followed by hourly measurements thereafter. The PC20 to allergen data of participating patients are given in table 1 .

\section{Skin-prick test}

This test was performed according to the European Academy of Allergology and Clinical Immunology position paper technique [23]. A drop of test solution of the allergen used in the allergen inhalation challenge was applied to the skin of the volar side of the forearm via a lancet with a 1-mm tip (Allergolisk Laboratorium, Copenhagen, Denmark). The test was performed using allergen at five different concentrations $(6,24,94,375$ and, $\left.1500 \mathrm{BU} \cdot \mathrm{mL}^{-1}\right)$. After $20 \mathrm{~min}$, the reactions were evaluated. Skin sensitivity to allergen was defined as the lowest allergen concentration that gave a weal of $\geq 2 \mathrm{~mm}$ in diameter [22].

\section{Measurement of total and allergen-specific serum immu- noglobulin $E$}

Total IgE concentrations were measured using a paper radioimmunosorbent test (PRIST; Pharmacia, Uppsala, Sweden) [24] according to the manufacturer's instructions. The results were expressed in $\mathrm{kU} \cdot \mathrm{L}^{-1}$. Specific IgE antibodies to house dust mite, cat, dog and rabbit allergen were measured using the CAP method (Pharmacia \& Upjohn, Uppsala, Sweden) [24], and the results, again, are expressed in $\mathrm{kU} \cdot \mathrm{L}^{-1}$.

\section{Isolation of eosinophils}

Blood was anticoagulated with $0.4 \%$ trisodium citrate $(\mathrm{pH} 7.4)$ and mixed granulocytes were isolated from the buffy coat as described before [25]. The granulocyte fraction was centrifuged for $20 \mathrm{~min}$ at room temperature $\left(20^{\circ} \mathrm{C}\right)$ over Percoll (density $1.084 \mathrm{~g} \cdot \mathrm{mL}^{-1}$, layered on 
Percoll with a density of $1.1 \mathrm{~g} \cdot \mathrm{mL}^{-1}$ ) to reduce the number of neutrophils. The eosinophil-enriched fraction was collected from the Percoll 1.084/1.1 interface. Eosinophils were subsequently isolated using the method described by Hansel et al. [26]. This isolation procedure makes use of the fact that, in marked contrast to neutrophils, eosinophils lack the epitope on Fc $\gamma \mathrm{R}$ III recognized by the monoclonal antibody CLB-FcR-gran 1[27]. As a result highly purified eosinophils can be isolated by removing neutrophils coated with FcR-gran-1 using immunomagnetic beads. In short: neutrophils were coated with a CD16 monoclonal antibody (CLB FcR-gran 1; 2 $\mu \mathrm{g} \cdot 10^{7}$ cells $\left.^{-1} \cdot \mathrm{mL}\right)$ for $20 \mathrm{~min}$ at $4^{\circ} \mathrm{C}$. Thereafter, the cells were washed twice and subsequently coincubated with dynabeads at a ratio of $1: 2$ (cells:beads) for $20 \mathrm{~min}$ at $4{ }^{\circ} \mathrm{C}$. Neutrophils were subsequently removed using a magnetic particle concentrator (MPC -1 ; Dynal, Oslo, Norway). Eosinophil purity was always $>95 \%$ with a viability of $>98 \%$, as judged by trypan blue exclusion.

\section{Measurement of the respiratory burst}

Eosinophils were suspended $\left(1.6 \times 10^{6}\right.$ cells. $\left.\mathrm{mL}^{-1}\right)$ in $N$-2-hydroxyethylpiperazine - $N$-2 - ethanesulphonic acid (HEPES) medium (20 mM HEPES, $132 \mathrm{mM} \mathrm{NaCl}, 6 \mathrm{mM}$

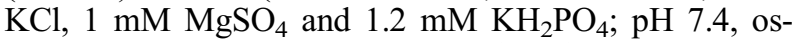
molarity $285 \mathrm{mOsm}$ ) supplemented with $1 \mathrm{mM} \mathrm{CaCl}$, $5 \mathrm{mM}$ glucose and $0.5 \%$ (weight/volume) human serum albumin, and preincubated $30 \mathrm{~min}$ at $37^{\circ} \mathrm{C}$. Thereafter, the cells were transferred to a stirred airtight vessel with a thermostat $\left(37^{\circ} \mathrm{C}\right)$ and stimulated with serum-treated zymosan (STZ) $\left(0.1 \mathrm{mg} \cdot \mathrm{mL}^{-1}\right)$. Oxygen consumption was measured using an oxygen probe (Yellow Springs Instrument, Yellow Springs, OH, USA). The maximal rate of oxygen uptake was calculated from the slope of the measured oxygen concentration of the cell suspension and expressed as nmol $\mathrm{O}_{2} \cdot \mathrm{min}^{-1} \cdot 10^{-6}$ cells.

\section{Measurement of platelet-activating factor}

All incubations were performed in enriched HEPES medium (see above). After a preincubation of $30 \mathrm{~min}$ with interleukin-5 (IL-5, $\left.10^{-11} \mathrm{M}\right)$ or buffer at $37^{\circ} \mathrm{C}, \mathrm{STZ}(0.5$ $\left.\mathrm{mg} \cdot \mathrm{mL}^{-1}\right)$ was added to the eosinophils $\left(10^{6}\right.$ cells $\left.\cdot \mathrm{mL}^{-1}\right)$ for a subsequent incubation of $30 \mathrm{~min}$ at $37^{\circ} \mathrm{C}$ in a vigorously shaking water bath. Thereafter, cells and zymosan particles were removed by centrifugation $\left(15 \mathrm{~min}, 2,000 \times \mathrm{g}, 4^{\circ} \mathrm{C}\right)$ and the supernatant collected and stored under nitrogen at $-70^{\circ} \mathrm{C}$. PAF was determined in these samples using a competitive radioimmunoassay (New England Nuclear, Boston, MA, USA).

\section{Measurement of serum eosinophil cationic protein}

For the measurement of ECP, SST tubes (Becton Dickinson, Plymouth, UK) were used. Serum was collected after centrifugation and a clotting time of 60-120 min [8]. ECP was measured using the CAP system (Pharmacia \& Upjohn).

\section{Statistical analysis}

All data are presented as mean \pm SEM except for total and specific serum IgE concentrations and the PC20 to histamine and to allergen, which are expressed as median values. Statistical evaluation of the data was performed with the statistical analysis program SPSS (SPSS Inc., Chicago, IL, USA) using Student's paired t-test. Differences between the groups were evaluated by one-way analysis of variance followed by the least significant difference (LSD) test. A p-value $<0.05$ was considered significant.

\section{Results}

The effect of treatment on pulmonary function forced expiratory volume in one second

In all treatment groups, a significant improvement in FEV1 (\% pred) was achieved after 4 weeks of treatment without further improvement after 8 weeks (beclomethasone group $\mathrm{p}=0.018$; salmeterol group $\mathrm{p}=0.014$; combination group $\mathrm{p}=0.006$ ). After 4 (visit 5) and 8 (visit 6) weeks of treatment no significant differences were found in improvement in FEV 1 between the three treatment groups (fig. 1).

The effect of allergen inhalation challenge on activation of oxygen radical production, degranulation of eosinophil cationic protein in serum and production of platelel-activating factor before therapy

Addition of opsonized particles (STZ) to human eosinophils results in activation of the respiratory burst [28]. This STZ response is very sensitive to priming by cytokines in vitro. Figure $2 \mathrm{a}$ shows the effect of allergen challenge on the STZ $\left(0.1 \mathrm{mg} \cdot \mathrm{mL}^{-1}\right.$, suboptimal concentration)-induced respiratory burst of eosinophils derived from allergic asthmatics. In the total patient population

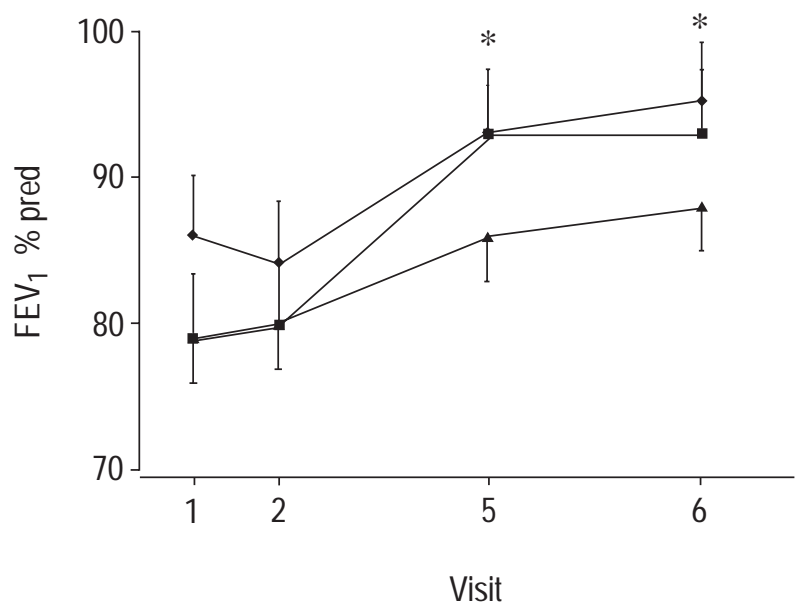

Fig. 1. - The effect of treatment on pulmonary function (forced expiratory volume in one second) during 8 weeks of treatment with beclomethasone dipropionate $(\bullet)$ salmeterol xinafoate $(\boldsymbol{\Delta})$ or both $(\boldsymbol{\square})$ in 40 patients with allergic asthma. Data are presented as mean \pm SEM. Visits 5 and 6 represent 4 and 8 weeks of treatment respectively. No significant difference was found in improvement in FEV1 between the groups. *: $\mathrm{p}<0.05$ versus baseline. 

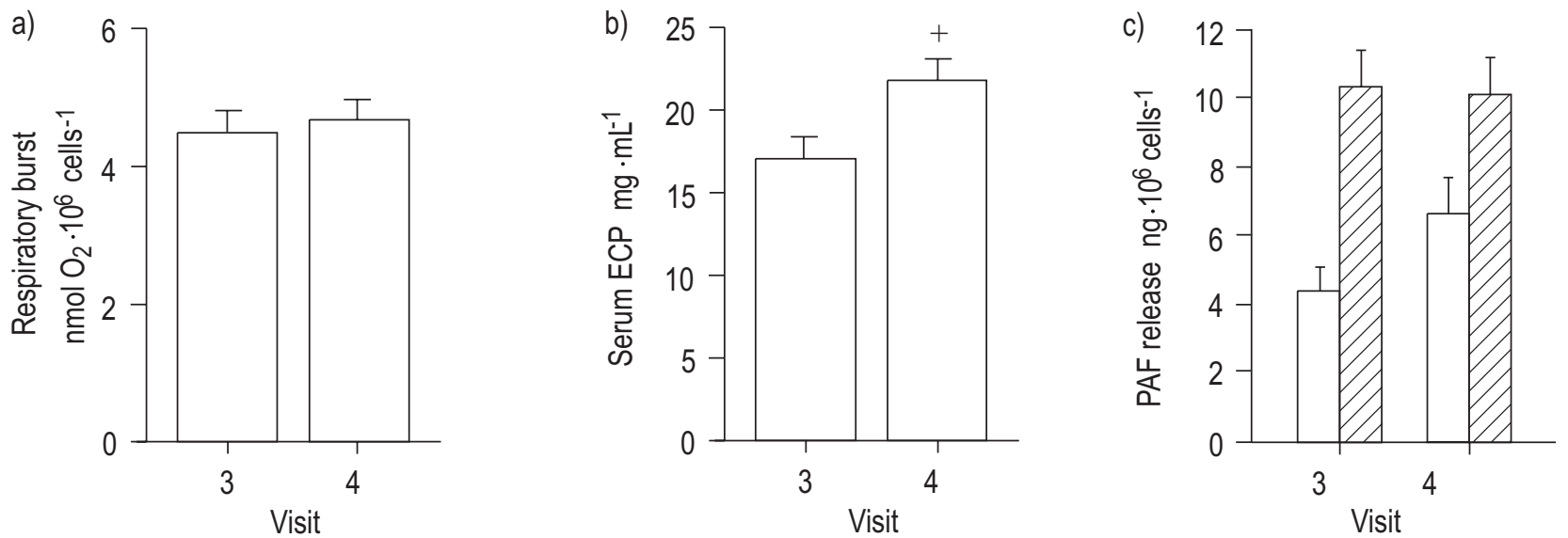

Fig. 2. - Effect of allergen challenge on: a) serum-treated zymosan STZ $\left(0.1 \mathrm{mg} \cdot \mathrm{mL}^{-1}\right)$-induced respiratory burst; b) serum eosinophil cationic protein concentration; and c) STZ-induced PAF-release by unprimed ( $\square$ ) and IL-5 primed eosinophils (ש) ). Respiratory burst results are expressed as maximal rate of oxygen consumption. Data are presented as mean \pm SEM of independent experiments in all patients $(\mathrm{n}=40)$. ${ }^{+}: \mathrm{p}=0.028$ versus visits 3 .

before therapy the respiratory burst was not significantly influenced $24 \mathrm{~h}$ postchallenge (visit 3 versus visit $4, \mathrm{n}=$ 40).

Serum ECP might serve as an indirect marker of preactivation or priming of human eosinophils in vivo, and is often used as a disease monitor in allergic asthma [4, 9]. Figure $2 \mathrm{~b}$ shows that before therapy serum ECP significantly increased after allergen challenge (visit 3 versus visit $4, \mathrm{p}=0.028$ ).

Figure $2 \mathrm{c}$ shows that before treatment allergen challenge did not significantly influence unprimed STZ-induced PAF-release in the total patient group (visit 3 versus visit $4, \mathrm{n}=40$ ). For optimal interaction of eosinophils with STZ the cells were primed with IL-5. It was found that pretreatment allergen challenge did not significantly influence IL-5-primed STZ-induced PAF-release (visit 3 versus visit $4, \mathrm{n}=40$ ).

The effect of treatment on activation of oxygen radical production, increase in serum eosinophil cationic protein concentration and production of platelet-activating factor before allergen challenge

The effect of treatment with salmeterol, beclomethasone or both on the STZ $\left(0.1 \mathrm{mg} \cdot \mathrm{mL}^{-1}\right.$, suboptimal concentration)-induced respiratory burst of eosinophils derived from allergic asthmatics before challenge is shown in figure 3 . Eight weeks of treatment with beclomethasone alone significantly inhibited the STZ-induced respiratory burst before allergen inhalation challenge (visit 3 versus visit 7 , $\mathrm{p}=0.034)$. In contrast to monotherapy with beclomethasone, the change in oxidase activity after monotherapy with salmeterol or combination therapy did not reach statistical significance (visit 3 versus visit 7).

Figure 4 shows that therapy did not significantly influence prechallenge serum ECP concentrations in all treatment groups (visit 3 versus visit 7). After treatment with salmeterol, beclomethasone or both, no significant effect on unprimed and IL-5-primed PAF-release in all patient groups (fig. 5a and b, respectively, visit 3 versus visit 7) was found.
The effect of allergen inhalation challenge on activation of oxygen radical production, degranulation of eosinophil cationic protein in serum and production of platelet-activating factor after therapy

The oxidase activity induced by STZ $\left(0.1 \mathrm{mg} \cdot \mathrm{mL}^{-1}\right)$ in the patients treated with salmeterol alone significantly increased after allergen challenge (fig. $3, p=0.007$ ) and was significantly higher compared to the combination group $(p=0.001)$. In both other patient groups, the respiratory burst was not significantly influenced by allergen challenge (visit 7 versus visit 8 ).

After monotherapy with salmeterol, the serum ECP concentration significantly increased after allergen challenge

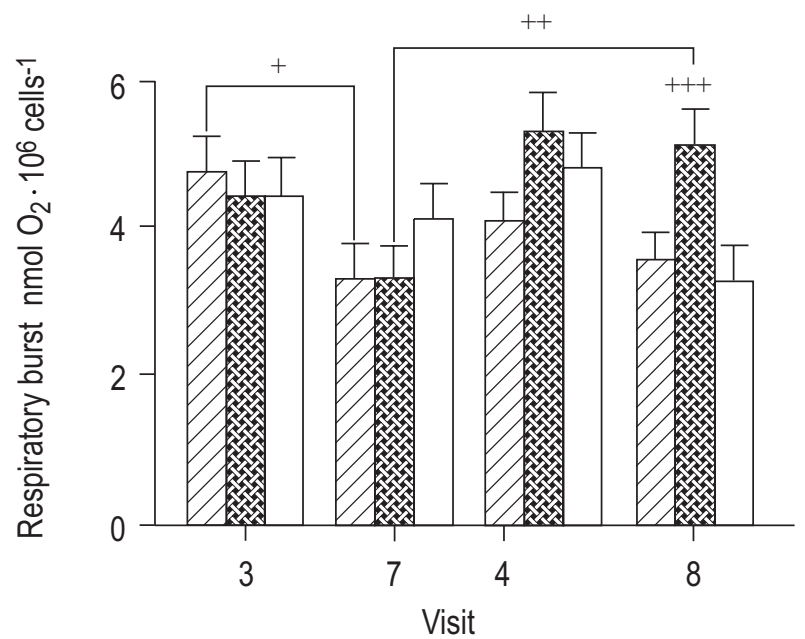

Fig. 3. - Effect of treatment and allergen challenge on serum-treated zymosan (STZ; $0.1 \mathrm{mg} \cdot \mathrm{mL}^{-1}$ )-induced respiratory burst by eosinophils in patients treated with beclomethasone dipropionate $(\mathbb{Z})$, salmeterol xinafoate (雄) or both $(\square)$. Respiratory burst results are expressed as mean \pm SEM maximal rate of oxygen consumption from independent experiments within the different treatment groups. Visit 3: allergen inhalation challenge performed $24 \mathrm{~h}$ before start of 8 -week treatment period; visit 4: histamine inhalation challenge at start of treatment; visit 7: allergen inhalation challenged performed $48 \mathrm{~h}$ after end of treatment; visit 8 : histamine inhalation challenge $24 \mathrm{~h}$ after visit $7 .^{+}: \mathrm{p}=0.034 ;^{++}$ $\mathrm{p}=0.007$; significantly different to the combination group $(\mathrm{p}=0.001){ }^{+++}$. $\mathrm{p}=0.016$. 


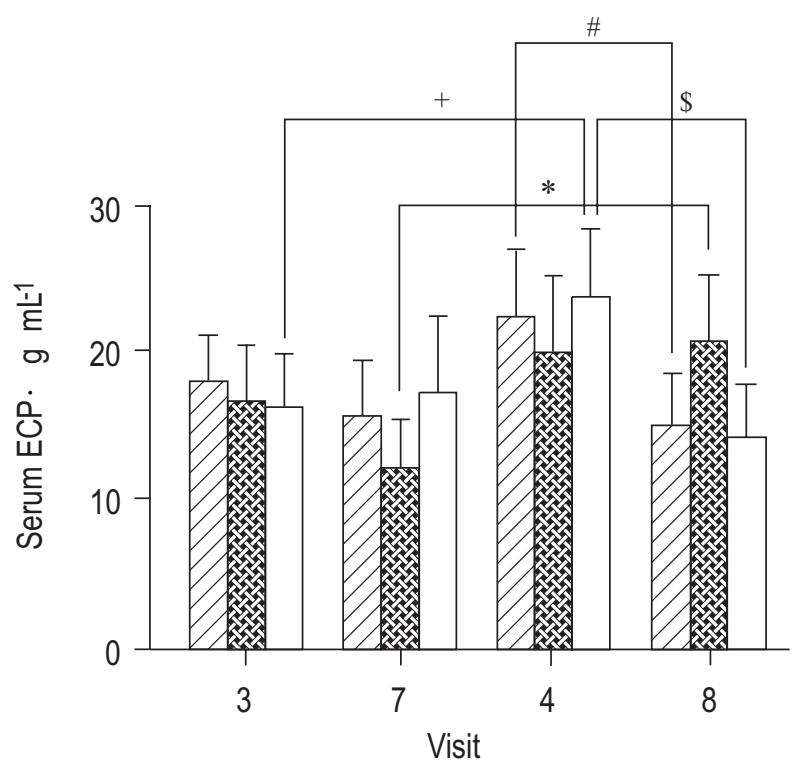

Fig. 4. - Effect of treatment and allergen challenge on serum eosinophil cationic protein (ECP) concentration in patients treated with beclomethasone dipropionate $(\mathbb{Z})$, salmeterol xinafoate (杽) or both $(\square)$. Data are presented as mean \pm SEM of independent experiments Visit 3: allergen inhalation challenge performed $24 \mathrm{~h}$ before start of 8 -week treatment period; visit 4: histamine inhalation challenge at start of treatment; visit 7: allergen inhalation challenged performed $48 \mathrm{~h}$ after end of treatment; visit 8 : histamine inhalation challenge $24 \mathrm{~h}$ after visit 7 within the different treatment groups. ${ }^{+}: \mathrm{p}=0.007 ; *: \mathrm{p}=0.05$, significantly different to patients treated with beclomethasone alone or the combination group $(\mathrm{p}=0.038) ;{ }^{\#}: \mathrm{p}=0.025 ;{ }^{\$} ; \mathrm{p}=0.004$.

(fig. $4 ; p=0.005)$. This change in serum ECP levels induced by allergen challenge after monotherapy with salmeterol alone was significantly higher compared to ECP concentration changes after therapy with beclomethasone alone or the combination ( $\mathrm{p}=0.038$ ). No significant effect of allergen challenge after therapy on serum ECP samples was found in patients treated with beclomethasone alone or the combination (visit 7 versus visit 8 ).

Figure 5 shows that allergen challenge after therapy did not significantly influence unprimed and IL-5-primed PAF-release in all treatment groups. The change in unprimed PAF release at visit 8 compared to visit 7 was significantly lower after combination therapy compared to monotherapy with beclomethasone (fig. $5 \mathrm{a}, \mathrm{p}=0.029$ ). The change in IL-5 primed PAF release at visit 8 compared to visit 7 was significantly lower after combination therapy compared to monotherapy with salmeterol (fig. $5 \mathrm{~b} ; \mathrm{p}=0.021$ ).

The effect of treatment on activation of oxygen radical production, degranulation of eosinophil cationic protein in serum and production of platelet-activating factor at 24 hostchallenge

No effect of therapy was found on the postchallenge oxidase activity in all treatment groups (fig. 3, visit 4 versus visit 8 ). The postchallenge oxidase activity in the group treated with salmeterol alone (visit 8) was significantly higher compared to the other groups $(\mathrm{p}=0.016)$.

The postchallenge serum ECP concentrations were significantly lower after therapy with beclomethasone alone
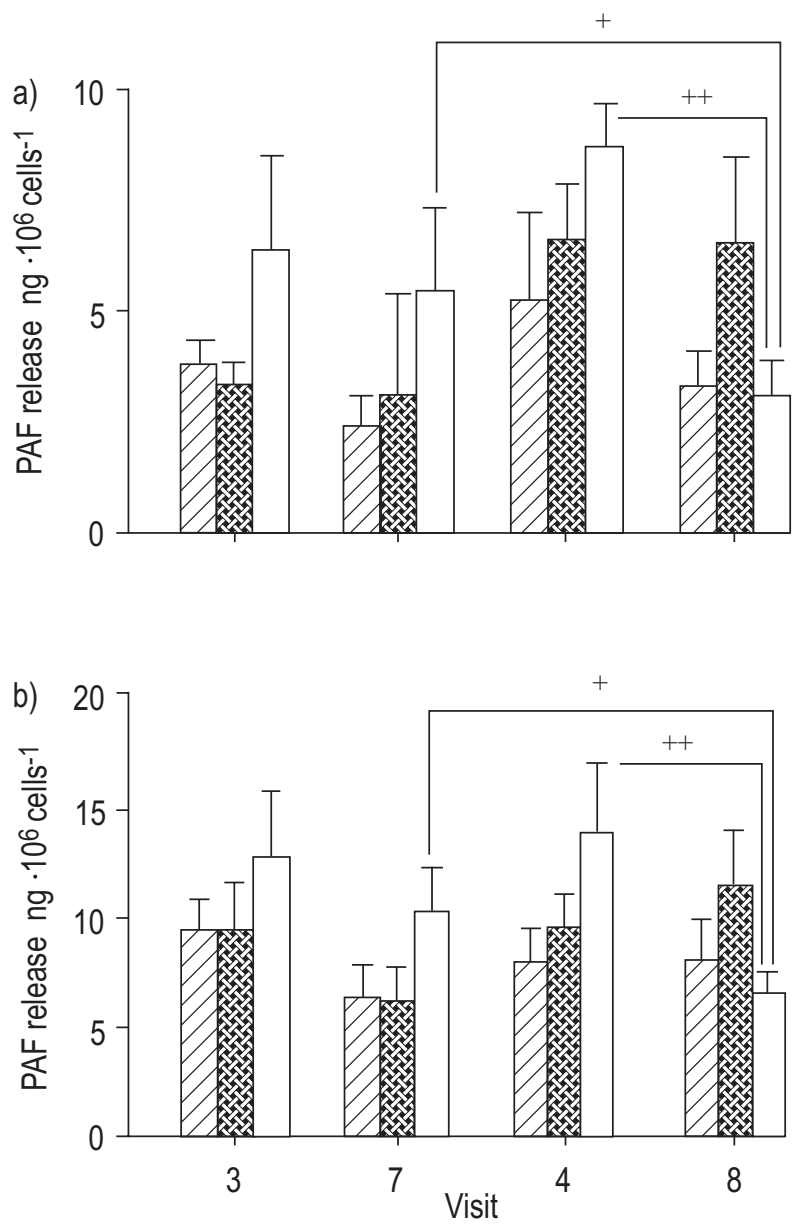

Fig. 5. - Effect of treatment and allergen challenge on serum-treated zymosan (STZ)-induced platelet-activating factor (PAF)-release by: a) unprimed; and b) IL-5 primed eosinophils in patients treated with beclomethasone dipropionate $(\mathbb{Z})$, salmeterol xinafoate (ख) or both $(\square)$. Data are presented as mean \pm SEM of independent experiments within the different treatment groups. Visit 3: allergen inhalation challenge performed $24 \mathrm{~h}$ before start of 8-week treatment period; visit 4: histamine inhalation challenge at start of treatment; visit 7: allergen inhalation challenged performed $48 \mathrm{~h}$ after end of treatment; visit 8: histamine inhalation challenge $24 \mathrm{~h}$ after visit 7 . a) ${ }^{+}: \mathrm{p}=0.029$ versus beclomethasone; ${ }^{++}$: $\mathrm{p}=0.012$; and $\mathrm{b}){ }^{+}: \mathrm{p}=0.021$ versus salmeterol; ${ }^{++}: \mathrm{p}=0.041$.

or the combination ( $\mathrm{p}=0.025$ and $\mathrm{p}=0.004$, respectively) than before therapy (fig. 4 , visit 4 versus visit 8 ). No therapy effect on postchallenge serum ECP concentrations was seen after monotherapy with salmeterol.

The postchallenge unprimed and IL-5 primed PAFrelease was significantly lower after therapy with the combination ( $\mathrm{p}=0.012$ and $\mathrm{p}=0.041$, respectively) than before treatment and $24 \mathrm{~h}$ postchallenge (fig. 55 and a; visit 4 versus visit 8). No effect was seen on postchallenge unprimed and IL-5-primed PAF-release after monotherapy with salmeterol or beclomethasone.

\section{Discussion}

This study set out to use the priming status of eosinophils in peripheral blood as a means of monitoring inflammatory processes in the lung before and after treatment. The effects of the antiasthma drugs beclomethasone dipropionate and salmeterol xinafoate alone and in combination 
were investigated in the context of antagonism of primingsensitive eosinophil cytotoxic mechanisms, i.e. degranulation of ECP in serum, respiratory burst and PAF release. These effects were studied before and $24 \mathrm{~h}$ after allergen inhalation challenge. Also, pulmonary function (FEV1) was measured during the treatment period, and showed no difference in improvement between the three treatment groups.

First, the effect of allergen inhalation challenge before therapy on the different responses of eosinophils $(n=40$, visit 3 versus visit 4) was investigated. A significant effect of allergen challenge was found on serum ECP levels (fig. $2 b)$. This result is in agreement with the finding of Pedersen et al. [29], who also found a significant increase in serum ECP levels $24 \mathrm{~h}$ postchallenge in a study in 12 asthmatic patients. Allergen challenge did not significantly influence STZ $\left(0.1 \mathrm{mg} \cdot \mathrm{mL}^{-1}\right)$-induced oxidase activity (fig. 2a) and STZ-induced PAF-release in all patient groups (fig. 2c). These data indicate the absence of primed eosinophils (in the context of respiratory burst activation and PAF release) $24 \mathrm{~h}$ postchallenge. In previous studies on eosinophil chemotaxis, it was shown, however, that bronchoprovocation leads to further priming of eosinophils [8]. In this previous report, blood was drawn approximately $5 \mathrm{~h}$ after challenge. It is tempting to speculate that primed cells extravasate in a $24 \mathrm{~h}$ time window and that probably more effects of challenge might have been measured had blood been drawn at an earlier timepoint. Indeed, the fact that the unprimed PAF release showed a trend to increase after challenge $(\mathrm{p}=0.09)$ may support this hypothesis.

The effect of therapy before challenge (visit 3 versus visit 7) was then studied. Therapy with beclomethasone alone inhibited prechallenge STZ $\left(0.1 \mathrm{mg} \cdot \mathrm{mL}^{-1}\right)$-induced respiratory burst (fig. 3). Furthermore, no significant effect of therapy on prechallenge serum ECP concentrations and STZ-induced PAF-release was found in all patient groups (figs. 4 and 5). These results are in agreement with the findings of Tool et al. [17] who found that salmeterol could not inhibit PAF-synthesis in granulocyte-macrophage colony-stimulating factor-primed eosinophils. Furthermore, the findings agreed with the results of PEDERSEN et al. [29] who found no effect of salmeterol on prechallenge serum ECP levels.

Next, the effect of allergen challenge after therapy (visit 7 versus visit 8) was examined. After monotherapy with salmeterol, the postchallenge serum ECP concentration and STZ $\left(0.1 \mathrm{mg} \cdot \mathrm{mL}^{-1}\right)$-induced respiratory burst were significantly higher compared to prechallenge (figs. 3 and $4)$. These results are in contrast with the findings of Pedersen et al. [29], who found an inhibition of the increase in serum ECP levels at $24 \mathrm{~h}$ postchallenge after a single $50 \mu \mathrm{g}$ dose of salmeterol. Together with the increase in STZ $\left(0.1 \mathrm{mg} \cdot \mathrm{mL}^{-1}\right)$-induced respiratory burst at $24 \mathrm{~h}$ postchallenge to prechallenge in patients treated with salmeterol alone, it is tempting to speculate that monotherapy with salmeterol may even enhance eosinophil priming in peripheral blood. This might be explained by more inflammation in the bronchial tissue leading to enhanced production of cytokines. An alternative hypothesis is inhibition of extravasation of primed eosinophils into the bronchial tissue. This latter hypothesis is strengthened by the finding that salmeterol inhibits eosinophil chemotaxis in vitro [17].
Finally, the effects of therapy on eosinophil responses 24 $\mathrm{h}$ postchallenge were studied (visit 4 versus visit 8 ). No effect of therapy was found on the postchallenge STZ $(0.1$ $\left.\mathrm{mg} \cdot \mathrm{mL}^{-1}\right)$-induced oxidase activity in all treatment groups. The postchallenge serum ECP concentrations were significantly lower after therapy with the combination and beclomethasone alone compared to before therapy. This latter result is in contrast with the finding of PIZZICHINI et al. [30], who found no reduction in the increase in serum ECP levels after pretreatment with beclomethasone. A possible explanation for this observation is that, in contrast to the study of Pizzichini et al. [30], in which a single dose of beclomethasone was given, in the present study, the inhaled steroid was given regularly for 8 weeks. Interestingly, in contrast to the study of PEDERSEN et al. [29], who found that a single $50 \mu \mathrm{g}$ dose of salmeterol could prevent the allergen-induced rise in serum ECP levels, inhibition of the allergen-induced increase in serum ECP levels after 8 weeks' monotherapy with salmeterol could be demonstrated.

No effects on postchallenge PAF-release were seen after monotherapy with salmeterol or beclomethasone. After treatment, the change in unprimed PAF-release postchallenge compared to prechallenge was significantly lower in the combination group compared to the group treated with beclomethasone alone (fig. 5a). This result, together with the finding that only combination therapy inhibited both primed and unprimed PAF-release at $24 \mathrm{~h}$ postchallenge (fig. 5), suggests a possible additional anti-inflammatory effect of the combination of salmeterol and beclomethasone compared to therapy with beclomethasone alone.

In conclusion, the present results demonstrate that treatment with the combination of salmeterol and beclomethasone leads to inhibition of several responses associated with eosinophil priming. Therefore, standard therapy for moderate-to-severe asthmatics leads to inhibition of several priming processes of eosinophils. It is now tempting to speculate that inhibition of inflammatory processes in the bronchial tissue is reflected by the priming status of peripheral blood eosinophils. This priming phenotype might therefore be a good marker of tissue inflammation provided that convenient methods are developed to monitor priming.

\section{References}

1. Bousquet J, Chanez P, Lacoste JY, et al. Eosinophilic inflammation in asthma. N Engl J Med 1990; 323: $1033-$ 1039.

2. Warringa RAJ, Mengelers HJJ, Kuiper PHM, Raaijmakers JAM, Bruijnzeel PLB, Koenderman L. In vivo priming of platelet-activating factor-induced eosinophil chemotaxis in allergic asthmatic individuals. Blood 1992; 79: 18361841.

3. Koenderman L, Bruijnzeel PLB. Increased sensitivity of the chemo-attractant-induced chemiluminescence in eosinophils isolated from atopic individuals. Immunology 1989; 67: 534-540.

4. Venge P. Serum measurements of eosinophil cationic protein (ECP) in bronchial asthma. Clin Exp Allergy 1993; 23, Suppl. 2: 3-7.

5. Carlson M, Hakansson L, Kampe M, Stalenheim G, Peterson C, Venge P. Degranulation of eosinophils from 
pollen atopic patients with asthma is increased during pollen season. J Allergy Clin Immunol 1992; 89: 131139.

6. Cockcroft DW, Ruffin RE, Dolovich J, Hargreave FE. Allergen-induced increase in non-allergic bronchial reactivity. Clin Allergy 1977; 7: 503-513.

7. Busse WW. Mechanisms of inflammation and their therapeutic implications in the asthmatic patient. Ann Allergy 1992; 69: 261-266.

8. Warringa RAJ, Mengelers HJJ, Raaijmakers JAM, Bruijnzeel PLB, Koenderman L. Upregulation of formylpeptide and interleukin-8-induced eosinophil chemotaxis in patients with allergic asthma. J Allergy Clin Immunol 1993; 91: 1198-1205.

9. Dahl R, Venge P, Olsson I. Variations of blood eosinophils and cosinophil cationic protein in serum in patients with bronchial asthma. Allergy 1978; 33: 211-215.

10. Frick WE, Sedgwick JB, Busse WW. The appearance of hypodense eosinophils in antigen-dependant late phase asthma. Am Rev Respir Dis 1989; 139: 1401-1406.

11. National Heart Lung, and Blood Institute. International consensus report on diagnosis and treatment of asthma. Eur Respir J 1992; 5: 604-641.

12. Greening AP, Ind PW, Nordifield M, Shaw G. Added salmeterol versus higher-dose corticosteroid in asthma patients with symptoms on existing inhaled corticosteroid. Lancet 1994; 344: 219-224.

13. Woolcock A, Lundback B, Ringdal N, Jacques LA. Comparison of addition of salmeterol to inhaled steroids with doubling of the dose of inhaled steroids. Am J Respir Crit Care Med 1996; 153: 1481-1488.

14. Pauwels RA, Löfdahl C, Postma DS, et al. Effect of inhaled formoterol and budesonide on exacerbations of asthma. N Engl J Med 1997; 337: 1405-1411.

15. Butchers PR, Vardey G, Johnson M. Salmeterol: a potent and long-acting inhibitor of inflammatory mediator release from human lung. Br J Pharmacol 1991; 104: 672676.

16. Whelan CJ, Johnson M. Salmeterol inhibits granulocyte accumulation in guinea-pig lung. Br J Pharmacol 1991; 102: 176P

17. Tool ATJ, Mul FPJ, Knol EF, Verhoeven AJ, Roos D. The effect of salmeterol and nimesulide on chemotaxis and synthesis of PAF and LTC4 by human eosinophils. Eur Respir J 1996; 9: Suppl. 22: 141s-145s.

18. Twentyman OP, Finnerty JP, Harris A, Palmer J, Holgate ST. Protection against allergen-induced asthma by salmeterol. Lancet 1990; 336: 1338-1342.

19. American Thoracic Society. Standards for the diagnosis and care of patients with chronic obstructive pulmonary disease (COPD) and asthma. Am Rev Respir Dis 1987; 136: $225-244$.

20. Cockcroft DW, Killian DN, Mellon JJ, Hargreave FE. Bronchial reactivity to inhaled histamine: a method and clinical survey. Clin Allergy 1977; 7: 235-243.

21. Sterk PJ, Fabbri LM, Quanjer PH, et al. Airway responsiveness: standardized challenge testing with pharmacological, physical and sensitizing stimuli in adults. Eur Respir J 1993; 6: Suppl.16: 53-83.

22. Cockcroft DW, Murdock KY, Kirby J, Hargreave F. Prediction of airway responsiveness to allergen from skin sensitivity to allergen and airway responsiveness to histamine. Am Rev Respir Dis 1987; 135: 264-267.

23. Dreborg S, Backman A, Bosomba A, Bousquet J, Dieges P, Mailing HJ. Skin tests used in type I allergy testing. Position paper. Prepared by the subcommittee on Skin Tests of the European Academy of Allergology and Clinical Immunology. Allergy 1989; 44: Suppl. 10: 1-59.

24. Bousquet J, Chanez P, Chanal I, Michel FB. Comparison between RAST and Pharmacia CAP system: a new automated specific IgE assay. J Allergy Clin Immunol 1990; 85: 1039-1043.

25. Koenderman L, Kok PT, Hamelink ML, Verhoeven AJ, Bruijnzeel PLB. An improved method for the isolation of eosinophilic granulocytes from peripheral blood of normal individuals. J Leukoc Biol 1988; 44: 79-86.

26. Hansel TT, Pound JD, Pilling D, Kitas GD, Salmon M, Gentle TA, Lee SS, Thompson RA. Purification of human blood eosinophils by negative selection using immunomagnetic beads. J Immunol Methods 1989; 122: 97-103.

27. Hartnell A, Kay AB, Wardlaw AJ. IFN- $\gamma$ induces expression of Fc $\gamma$ RIII (CD16) on human eosinophils. $J$ Immunol 1992; 148: 1471-1478.

28. van der Bruggen T, Kok PTM, Raaijmakers JAM, et al. Cytokine priming of the respiratory burst in human eosinophils is $\mathrm{Ca}^{2+}$ independent and accompanied by induction of tyrosine kinase activity. J Leukoc Biol 1993; 53: 347-353.

29. Pedersen B, Dahl R, Larsen BB, Venge P. The effect of salmeterol on the early- and late-phase reaction to bronchial allergen and postchallenge variation in bronchial reactivity, blood eosinophils, serum eosinophil cationic protein, and serum eosinophil protein X. Allergy 1993; 48: 377-382.

30. Pizzichini MMM, Kidney JC, Wong BJO, et al. Effect of salmeterol compared with beclomethasone on allergeninduced asthmatic and inflammatory responses. Eur Respir J 1996; 9: 449-455. 